\section{A phase II multicenter study of the anti-CD19 antibody drug conjugate coltuximab ravtansine (SAR3419) in patients with relapsed or refrac- tory diffuse large B-cell lymphoma previously treated with rituximab-based immunotherapy}

\begin{abstract}
Marek Trnĕný,${ }^{1}$ Gregor Verhoef, ${ }^{2}$ Martin JS Dyer, ${ }^{3}$ Dina Ben Yehuda, ${ }^{4}$ Caterina Patti, ${ }^{5}$ Miguel Canales, ${ }^{6}$ Andrés Lopez, ${ }^{7}$ Farrukh T Awan, ${ }^{8}$ Paul G Montgomery, ${ }^{9}$ Andrea Janikova, ${ }^{10}$ Anna M Barbui, ${ }^{11}$ Kazimierz Sulek, ${ }^{12}$ Maria J Terol, ${ }^{13}$ John Radford, ${ }^{14}$ Anna Guidetti, ${ }^{15,16}$ Massimo Di Nicola, ${ }^{15}$ Laure Siraudin, ${ }^{17}$ Laurence Hatteville, ${ }^{18}$ Sandrine Schwab, ${ }^{19}$ Corina Oprea ${ }^{18}$ and Alessandro M Gianni ${ }^{15,16}$

${ }^{1}$ Charles University, General Hospital, Prague, Czech Republic; '2Department of Hematology, University Hospital, Leuven, Belgium; ${ }^{3}$ Ernest and Helen Scott Haematological Research Institute, University of Leicester, UK; ${ }^{4}$ Hadassah Medical Center, Jerusalem, Israel; ${ }^{5}$ PA Cervello EMAT, Palermo, Italy; ${ }^{6}$ Hospital la Paz, Madrid, Spain; ${ }^{7}$ Vall d'Hebron Research Institute, Barcelona, Spain; ${ }^{8}$ Ohio State University, Columbus, OH, USA; ${ }^{9}$ Boise VA Medical Center, Boise, ID, USA; ${ }^{10}$ Department of Hematology and Oncology, University Hospital Brno, Czech Republic; ${ }^{11}$ Azienda Ospedaliera Papa Giovanni XXIII, Bergamo, Italy; ${ }^{12}$ Wojskowy Instytut Medyczny, Warsaw, Poland; ${ }^{13}$ Hospital Clínico Universitario de Valencia, Health Research Institute INCLIVA, Spain; ${ }^{14}$ University of Manchester and The Christie NHS Foundation Trust, Manchester Academic Health Science Centre, UK; ${ }^{15}$ Fondazione Istituto Nazionale Tumori, Milan, Italy; ${ }^{16}$ University of Milan, Italy; ${ }^{17}$ Lincoln, Paris, France; ${ }^{18}$ Sanofi R\&D, Vitry sur Seine, France and ${ }^{19}$ Sanofi R\&D, Chilly-Mazarin, France
\end{abstract}

Haematologica 2018

Volume 103(8):1351-1358

\section{ABSTRACT}

T his phase II, single-arm, multicenter study examined the efficacy and safety of coltuximab ravtansine (an anti-CD19 antibody drug conjugate) in 61 patients with histologically documented (de novo or transformed) relapsed or refractory diffuse large B-cell lymphoma who had previously received rituximab-containing immuno-chemotherapy. Patients had received a median of 2.0 (range 0-9) prior treatment regimens for diffuse large B-cell lymphoma and almost half $(45.9 \%)$ had bulky disease $(\geq 1$ lesion $>5 \mathrm{~cm}$ ) at trial entry. Patients received coltuximab ravtansine $\left(55 \mathrm{mg} / \mathrm{m}^{2}\right)$ in 4 weekly and 4 biweekly administrations until disease progression or unacceptable toxicity. Forty-one patients were eligible for inclusion in the per protocol population. Overall response rate (International Working Group criteria) in the per protocol population, the primary end point, was 18/41 [43.9\%; 90\% confidence interval (CI:) 30.6-57.9\%]. Median duration of response, progressionfree survival, and overall survival (all treated patients) were 4.7 (range 0.0-8.8) months, 4.4 (90\%CI: 3.02-5.78) months, and 9.2 (90\% CI: 6.5712.09) months, respectively. Common non-hematologic adverse events included asthenia/fatigue (30\%), nausea (23\%), and diarrhea (20\%). Grade 3-4 adverse events were reported in 23 patients (38\%), the most frequent being hepatotoxicity (3\%) and abdominal pain (3\%). Eye disorders occurred in 15 patients (25\%); all were grade 1-2 and none required a dose modification. Coltuximab ravtansine monotherapy was well tolerated and resulted in moderate clinical responses in pre-treated patients with relapsed/refractory diffuse large B-cell lymphoma. (Registered at: clinicaltrials.gov identifier: 01472887)

\section{Correspondence:}

trneny@cesnet.cz

Received: April 10, 2017.

Accepted: May 3, 2018.

Pre-published: May 10, 2018.

doi:10.3324/haematol.2017.168401

Check the online version for the most updated information on this article, online supplements, and information on authorship \& disclosures: www.haematologica.org/content/103/8/1351

(C)2018 Ferrata Storti Foundation

Material published in Haematologica is covered by copyright. All rights are reserved to the Ferrata Storti Foundation. Use of published material is allowed under the following terms and conditions:

https://creativecommons.org/licenses/by-nc/4.0/legalcode. Copies of published material are allowed for personal or internal use. Sharing published material for non-commercial purposes is subject to the following conditions:

https://creativecommons.org/licenses/by-nc/4.0/legalcode, sect. 3. Reproducing and sharing published material for commercial purposes is not allowed without permission in writing from the publisher. 


\section{Introduction}

Diffuse large B-cell lymphoma (DLBCL) is the most frequent form of non-Hodgkin lymphoma, representing approximately $30-58 \%$ of cases. ${ }^{1}$ The majority of cases of DLBCL occur de novo, although some develop from indolent lymphoma. ${ }^{2}$ DLBCL is subclassified as germinal center B-cell-like (GCB) or activated B-cell-like (ABC) subtypes based on gene expression profiling. The $A B C$ subtype has a worse prognosis than the GCB subtype. ${ }^{3}$ In addition, concurrent deregulation of $M Y C$ and $B C L 2$ has been associated with poor outcomes, ${ }^{4,5}$ however the prognostic significance of these rearrangements remains controversial. $^{6-8}$

Standard first-line therapy for DLBCL is cyclophosphamide, hydroxydaunorubicin, vincristine, and prednisone, combined with rituximab (R-CHOP). Five-year overall survival (OS) in patients treated with this regimen is over $70 \%{ }^{9,10}$ Dose-adjusted etoposide, prednisone, vincristine, cyclophosphamide, doxorubicin, and rituximab (DA-EPOCH-R), showed promise as an alternative firstline regimen to $\mathrm{R}-\mathrm{CHOP}$ in a phase II study, ${ }^{11}$ but failed to demonstrate superior event-free survival or $O S$ in a phase III trial which directly compared the two regimens..$^{12}$ The majority of patients in the phase III study had good prognostic features, and therefore it is possible that DAEPOCH-R may provide an advantage in patients with an adverse prognosis (such as MYC/BCL2 double-hit lymphoma) or rare subtypes (such as primary mediastinal lymphoma). However, the phase III study was not designed to answer this question, and $\mathrm{R}-\mathrm{CHOP}$ remains the standard of care for the majority of unselected patients with DLBCL. ${ }^{12-15}$ Salvage treatment with autologous stem cell transplantation (ASCT) is the most effective approach at first relapse. However, it can only be offered to young, fit patients, and long-term survival is only $40 \% .{ }^{16}$ There are limited treatment options with unsatisfying results for patients relapsing after, or ineligible for, ASCT. ${ }^{77}$ New therapeutic strategies are essential for these patients.

Coltuximab ravtansine (SAR3419) is an anti-CD19 monoclonal antibody conjugated to a potent cytotoxic maytansinoid, DM4, via an optimized, hindered, disulfide bond. The antibody selectively binds to the CD19 antigen present on the majority of $B$ cells, resulting in internalization of the receptor-drug complex and intracellular release of DM4. DM4 is a potent inhibitor of tubulin polymerization and microtubule assembly, functioning by similar mechanisms to vincristine and vindesine. ${ }^{18,19}$

Coltuximab ravtansine has been evaluated in patients with relapsed/refractory (R/R) B-cell non-Hodgkin lymphoma. A first-in-human phase I study examined several dose levels in 3-weekly administrations. At the maximum tolerated dose $\left(160 \mathrm{mg} / \mathrm{m}^{2}\right)$ few clinical responses and high levels of treatment-related ocular toxicity were observed. ${ }^{20}$ A further phase I, dose-escalation study examined onceweekly dosing and a modified schedule consisting of 4 weekly doses followed by 4 doses given once every 2 weeks. Both schedules showed anti-lymphoma activity in approximately $30 \%$ of patients with either indolent or aggressive disease. The maximum tolerated dose was 55 $\mathrm{mg} / \mathrm{m}^{2}$, and the modified dosing schedule was found to limit drug accumulation, reduce toxicity, and improve response rates. ${ }^{19}$

To confirm the clinical benefit observed in the phase I setting in a population with aggressive lymphoma, we conducted a phase II, open-label, multicenter study evaluating coltuximab ravtansine monotherapy in transplantineligible patients with CD19-positive, R/R DLBCL.

\section{Methods}

\section{Study design}

In this phase II, open-label, single-arm study patients received 4 weekly doses of intravenous (iv) coltuximab ravtansine $55 \mathrm{mg} / \mathrm{m}^{2}$, followed by a 1 -week rest period, then biweekly doses until disease progression (PD), unacceptable toxicity, or discontinuation of treatment. One cycle was 4 weeks, except for cycle 1 ( 5 weeks). At the investigator's discretion, patients received premedication consisting of iv diphenhydramine $50 \mathrm{mg}$ and oral acetaminophen $650 \mathrm{mg}$ 30-45 minutes before each infusion. Dose reductions were permitted (see Online Supplementary Methods).

\section{Patients}

Adult patients with de novo or transformed histologically confirmed DLBCL and more than 30\% of cells expressing CD19 (local assessment) were enrolled. Patients had relapsed (progression $\geq 6$ months after completion of last line of therapy) or refractory (progression during or within 6 months of a prior therapy) disease and had previously received standard chemotherapy (including rituximab). Patients with primary refractory disease (refractory to first-line therapy) were ineligible. However, some primary refractory patients were wrongly enrolled (see Results section). Full inclusion and exclusion criteria are included in the Online Supplementary Appendix.

All patients provided written informed consent. The protocol and subsequent amendments were approved by independent ethics committees and/or institutional review boards at each center. The study was conducted according to the Declaration of Helsinki.

\section{Outcomes}

The primary end point was overall response rate [ORR; proportion of patients achieving a partial response (PR) or complete response (CR) (International Working Group criteria $\left.{ }^{21}\right)$ ]. Secondary end points included duration of response (DOR; time from first PR or CR until PD or death), progression-free survival (PFS; time from first study treatment until PD or death), OS (time from first study treatment until death), and safety. Assessment of biomarkers was an exploratory end point.

\section{Assessments}

Assessment of clinical response involved physical examination, bone marrow biopsy, and computerized tomography (CT) every 12 weeks until PD or treatment discontinuation. Positron-emission tomography (PET) was performed at baseline and, if positive, repeated to confirm a CR. Patients with a negative CT but positive PET were classified as PR.

Adverse events (AEs) were classified using National Cancer Institute Common Terminology Criteria for Adverse Events (v.4.03). Pre-specified AEs of special interest were eye disorders, neuropathy, and infusion-related reactions (all drug hypersensitivity reactions and treatment-related AEs occurring on the day of infusion).

Details of biomarker assessments are included in the Online Supplementary Methods.

\section{Statistical analysis}

The predicted beneficial ORR was $40 \%$ or over. Assuming 
44 patients were evaluable for response, the study had $90 \%$ power to reject the null hypothesis of an ORR of $20 \%$ with a onesided $\alpha=0.05$. An ORR of less than $20 \%$ was considered clinically uninteresting based on available observations from coltuximab ravtansine and new agents in relapsed/refractory non-Hodgkin lymphoma and/or DLBCL, for which activity ranged between $15 \%$ and $30 \%$ in phase II studies. ${ }^{22-28}$ The primary end point (ORR), was assessed in the per protocol (PP) population (all treated patients who had an evaluable response assessment during or at the end of treatment or who died due to PD before response assessment, without any important protocol deviations affecting efficacy at study entry). ORR was also assessed in the biomarkerevaluable population (all patients with results of biomarker analysis from a fresh or archival sample). DOR and PFS were assessed in the PP population, and OS and safety were assessed in all treated patients (safety population).

Statistical analyses of biomarkers are detailed in the Online Supplementary Appendix.

\section{Results}

Overall, 61 patients were enrolled (January 20, 2012 to July 23, 2013) and received at least one dose of study drug (safety population). Twenty patients were excluded from the PP population (Figure 1), of whom 16 were wrongly enrolled in the study due to misclassification of their prior treatment history. Of these 16 patients, primary refracto- ry disease was the sole important deviation at study entry in 14. The primary end point (ORR) was analyzed separately in this subgroup.

Baseline characteristics of the safety population are summarized in Table 1 . Most patients (50 of 61 patients; $82.0 \%$ ) presented with DLBCL at initial diagnosis. Of those patients with transformed lymphoma ( $n=11), 7$ were initially diagnosed with follicular lymphoma, and 9 had received prior anticancer therapy for non-DLBCL lymphoma ( 6 patients received $\geq 1$ prior anti-CD20-containing regimen). Almost half of the patients (45.9\%) had bulky disease (defined as longest diameter of the lesion $>5 \mathrm{~cm}$ for at least one location). Patients had received a median of 2.0 (range 0-9) prior treatment regimens for DLBCL, with 18 patients $(29.5 \%$ ) having received 3 or more prior regimens.

Patients received a median of 3 (range 1-10) cycles of therapy [median duration of treatment 13.3 (range 5-41) weeks]. Thirty-nine of 61 treated patients $(63.9 \%)$ received 3 or more treatment cycles, including 16 patients who received 6 cycles or more. Overall, 56 patients discontinued treatment due to: PD $(n=47)$, AEs $(n=6)$, or investigator's decision ( $n=3)$. At the time of analysis (May 6, 2014), 5 patients were continuing on therapy.

The ORR (primary end point), analyzed in the PP population ( $n=41$ ), was $43.9 \%$ (18 of 41 ; $90 \%$ CI: $30.6-57.9 \%$ ); therefore, the null hypothesis was rejected $(P<0.0001)$. Among the 18 responders, 6 achieved CR (PET negative) and 12 achieved PR [PET positive $(n=8)$ or not examined

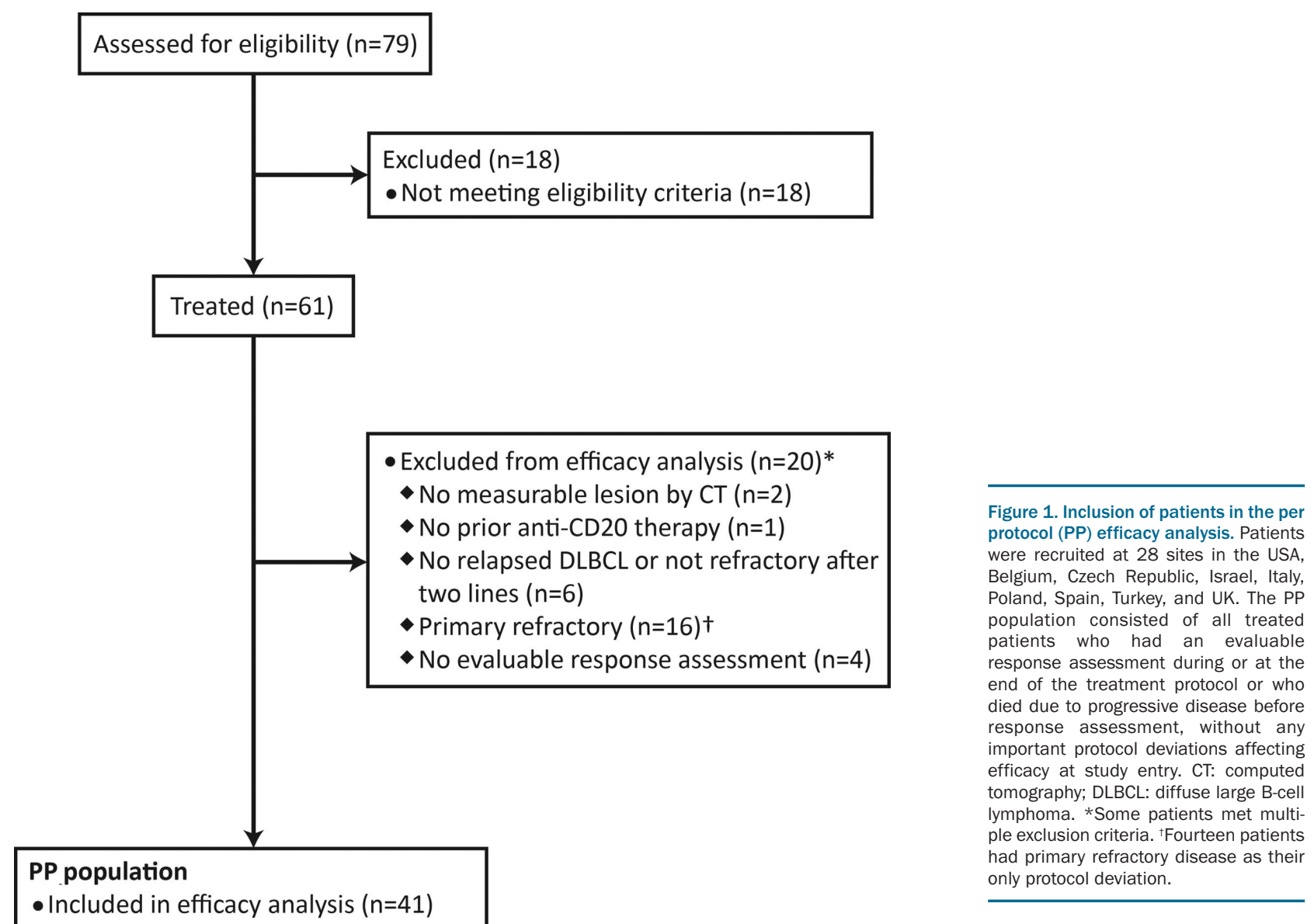


$(n=4)]$ (Table 2). Seven patients (7 of $41 ; 17.1 \%$ ) had stable disease, and the remaining patients (16 of $41 ; 39.0 \%$ ) had progressive disease. Higher response rates were observed among patients with relapsed DLBCL (14 of 26; 53.8\%, 90\% CI: $36.2-70.8 \%$ ) compared with patients refractory to their last regimen (4 of $15 ; 26.7 \%, 90 \% \mathrm{CI}: 9.7-51.1 \%$ ). A higher ORR (56.3\%) was also observed in patients who received only one prior therapeutic regimen $(n=16)$. At the time of analysis, 6 patients with relapsed disease were still responding to therapy (3 CRs and $3 \mathrm{PRs}$ ).

Table 1. Baseline characteristics (safety population; $n=61$ ).

\begin{tabular}{|c|c|}
\hline Variable & Value, $\mathbf{n}(\%)$ \\
\hline Median age (range), years & $69(30-88)$ \\
\hline $\begin{array}{l}\text { Age group, years } \\
<65 \\
65-75 \\
>75\end{array}$ & $\begin{array}{l}17(27.9 \%) \\
26(42.6 \%) \\
18(29.5 \%)\end{array}$ \\
\hline $\begin{array}{l}\text { Sex } \\
\text { Male } \\
\text { Female }\end{array}$ & $\begin{array}{l}31(50.8 \%) \\
30(49.2 \%)\end{array}$ \\
\hline $\begin{array}{l}\text { Histology (investigator determined) } \\
\text { De novo DLBCL } \\
\text { Transformed DLBCL }\end{array}$ & $\begin{array}{l}50(82.0 \%) \\
11(18.0 \%)\end{array}$ \\
\hline $\begin{array}{l}\text { Cell of origin classification* } \\
\text { ABC } \\
\text { GCB } \\
\text { Unclassified }\end{array}$ & $\begin{array}{l}16(43.2 \%) \\
17(45.9 \%) \\
4(10.8 \%)\end{array}$ \\
\hline $\begin{array}{l}\text { ECOG performance status } \\
0 \\
1 \\
2\end{array}$ & $\begin{array}{c}27(45.0 \%) \\
26(43.3 \%) \\
7(11.7 \%)\end{array}$ \\
\hline $\begin{array}{l}\text { Ann Arbor stage } \\
\text { I } \\
\text { II } \\
\text { III } \\
\text { IV }\end{array}$ & $\begin{array}{c}4(6.6 \%) \\
11(18.0 \%) \\
15(24.6 \%) \\
31(50.8 \%)\end{array}$ \\
\hline $\begin{array}{l}\text { International Prognostic Index score } \\
\text { Low } \\
\text { Low intermediate } \\
\text { High intermediate } \\
\text { High }\end{array}$ & $\begin{array}{l}12(19.7 \%) \\
11(18.0 \%) \\
25(41.0 \%) \\
13(21.3 \%)\end{array}$ \\
\hline Lactate dehydrogenase $>\mathrm{ULN}^{\dagger}$ & $41(68.3 \%)$ \\
\hline Extranodal involvement & $36(59.0 \%)$ \\
\hline Bulky disease ${ }^{\ddagger}$ & $28(45.9 \%)$ \\
\hline Prior transplant for DLBCL & $12(19.7 \%)$ \\
\hline $\begin{array}{l}\text { Disease status at study entry } \\
\text { Primary refractory } \\
\text { Refractory to last regimen } \\
\text { Relapsed }\end{array}$ & $\begin{array}{l}16(26.7 \%) \\
16(26.7 \%) \\
28(46.7 \%)\end{array}$ \\
\hline $\begin{array}{l}\text { Number of prior regimens for DLBCL } \\
0 \\
1 \\
2 \\
3 \\
>3\end{array}$ & $\begin{array}{c}1(1.6 \%) \\
25(41.0 \%) \\
17(27.9 \%) \\
9(14.8 \%) \\
9(14.8 \%)\end{array}$ \\
\hline Prior regimen for non-DLBCL lymphoma" & $9(81.8 \%)$ \\
\hline
\end{tabular}

Data are number (n) (\%) unless otherwise stated. ABC: activated B-cell-like; DLBCL diffuse large B-cell lymphoma; ECOG: Eastern Cooperative Oncology Group; GCB: germinal center B-cell-like; ULN: upper limit of normal. * $\mathrm{N}=37 .{ }^{\dagger} \mathrm{N}=60$. ${ }^{~}$ Longest diameter of lesion $>5 \mathrm{~cm}$ for at least 1 location. ${ }^{\circledR} \mathrm{N}=60$ (1 patient had received no prior regimen for DLBCL). ${ }^{\mathrm{T}} \mathrm{N}=11$ (patients with transformed DLBCL).
Overall response rate was also assessed in 14 patients with primary refractory disease (sole important deviation affecting efficacy) who were excluded from the PP population. Among these patients, the ORR was $21.4 \%$ (3 of 14; $90 \%$ CI: 6.1-46.6\%), with the majority having PD (9 of $14 ; 64.3 \%$ ) and only one patient achieving CR.

Figure 2 shows the DOR in individual patients in the PP population according to initial responses. The median DOR was 4.7 (range 0-8.8) months. Of 18 patients who responded to coltuximab ravtansine treatment (PR or better), 4 achieved a DOR of $>6$ months (one of 4 patients with refractory disease and 3 of 14 patients with relapsed disease). At the time of analysis, 34 of 41 patients (82.9\%) in the PP population had experienced PD and the median PFS was 4.4 (90\% CI: 3.02-5.78) months. Forty-one of the 61 patients in the safety population had died at the analysis cut-off date. Estimated median OS was $9.2(90 \% \mathrm{CI}$ : 6.57-12.09) months (Figure 3).

CD19 was locally assessed in all patients $(n=41)$ during enrollment, and centrally assessed in 37 of 41 PP patients $(90.2 \%)$ during biomarker analysis. Overall, 35 patients had $30 \%$ or more CD19-positive cells (range $30-100 \%$ ). Variable levels of expression were recorded, with 11, 16, and 8 samples having a mean intensity of $1+, 2+$, and $3+$, respectively. The median $\mathrm{H}$-score (see Online Supplementary Methods) was 162 (range 0-270). There was no relationship between levels of expression of CD19 and response; some patients with high CD19 expression had $\mathrm{PD}$ as their best response whereas some patients with lower expression experienced a PR (Online Supplementary Figure S1). Two patients with absent CD19 staining had progressive disease. For each measure of CD19 expression, the receiver operating characteristic curve AUC values varied between 0.42 and 0.65 , indicating that none of the CD19 expression measures showed good predictive accuracy for distinguishing between responders and nonresponders (Online Supplementary Table S1). No significant optimal cut-off point for CD19 expression was identified. In addition, there was no apparent correlation between cell of origin classification or MYC/BCL2 expression and response rate (data not shown).

All 61 patients in the safety population (Table 3) experienced at least one $\mathrm{AE}$, including 33 of 61 patients $(54 \%)$ who experienced at least one treatment-related AE. Grade 3-4 AEs were reported in 23 of 61 patients (38\%), the most frequent being hepatotoxicity (2 of $61,3 \%$ ) and abdominal pain (2 of $61,3 \%$ ). Serious AEs (SAEs) were reported in 24 of 61 patients (39\%). Six SAEs (occurring in

Table 2. Summary of best response to treatment by subgroup based on International Working Group criteria.

\begin{tabular}{lcccc}
$\begin{array}{l}\text { Response, } \\
\text { n (\%) }\end{array}$ & $\begin{array}{c}\text { All } \\
(\mathbf{n}=41)\end{array}$ & $\begin{array}{c}\text { Refractory to } \\
\text { last regimen } \\
(\mathbf{n}=\mathbf{1 5})\end{array}$ & $\begin{array}{c}\text { Relapsed } \\
(\mathbf{n}=26)\end{array}$ & $\begin{array}{c}\text { Primary } \\
\text { refiractory } \\
(\mathbf{n = 1 4})\end{array}$ \\
\hline ORR & $18(43.9 \%)$ & $4(26.7 \%)$ & $14(53.8 \%)$ & $3(21.4 \%)$ \\
$90 \% \mathrm{CI}^{*}$ & $30.6-57.9$ & $9.7-51.1$ & $36.2-70.8$ & $6.1-46.6$ \\
\hline CR & $6(14.6 \%)$ & $1(6.7 \%)$ & $5(19.2 \%)$ & $1(7.1 \%)$ \\
PR & $12(29.3 \%)$ & $3(20.0 \%)$ & $9(34.6 \%)$ & $2(14.3 \%)$ \\
\hline SD & $7(17.1 \%)$ & $3(20.0 \%)$ & $4(15.4 \%)$ & $2(14.3 \%)$ \\
PD & $16(39.0 \%)$ & $8(53.3 \%)$ & $8(30.8 \%)$ & $9(64.3 \%)$ \\
\hline
\end{tabular}

n: number; CI: confidence interval; CR: complete response; ORR: overall response rate; PD: progressive disease; PR: partial response; SD: stable disease. *Estimated by Clopper-Pearson exact method. 
3 patients) were considered related to treatment: hepatotoxicity $(n=2)$, pneumonia, abdominal pain, nausea, and grade 5 febrile neutropenia $(n=1)$.

The most common grade 3-4 hematologic laboratory abnormalities were neutropenia (25\%), lymphopenia $(21 \%)$, and leukopenia (15\%) (Table 3). Grade 3-4 nonhematologic laboratory abnormalities were rare, with elevated levels of aspartate aminotransferase, alkaline phosphatase, alanine aminotransferase, and creatinine each occurring in 2 patients. Grade 3-4 febrile neutropenia was also observed in one patient, but this did not require growth factor administration.
Eye disorders occurred in 15 patients (25\%); all were grade 1-2 and none required a dose modification. Nineteen extracorneal eye disorders were observed in 13 patients $(21.3 \%)$, with the first occurrence during cycle 1 (6 patients), cycle $2(n=2)$, cycle $3(n=3)$, cycle $7(n=1)$, and cycle $9(n=1)$. Fourteen of these events had resolved at the time of data cut-off, with a median recovery time of 12.5 days (range 1-47). One patient experienced a corneal event (grade 2 keratitis during cycle 4), which resolved within 9 days. A further 2 patients experienced dry eyes, occurring during cycle 1 and resolving after 13 and 17 days, respectively. Neuropathy was observed in
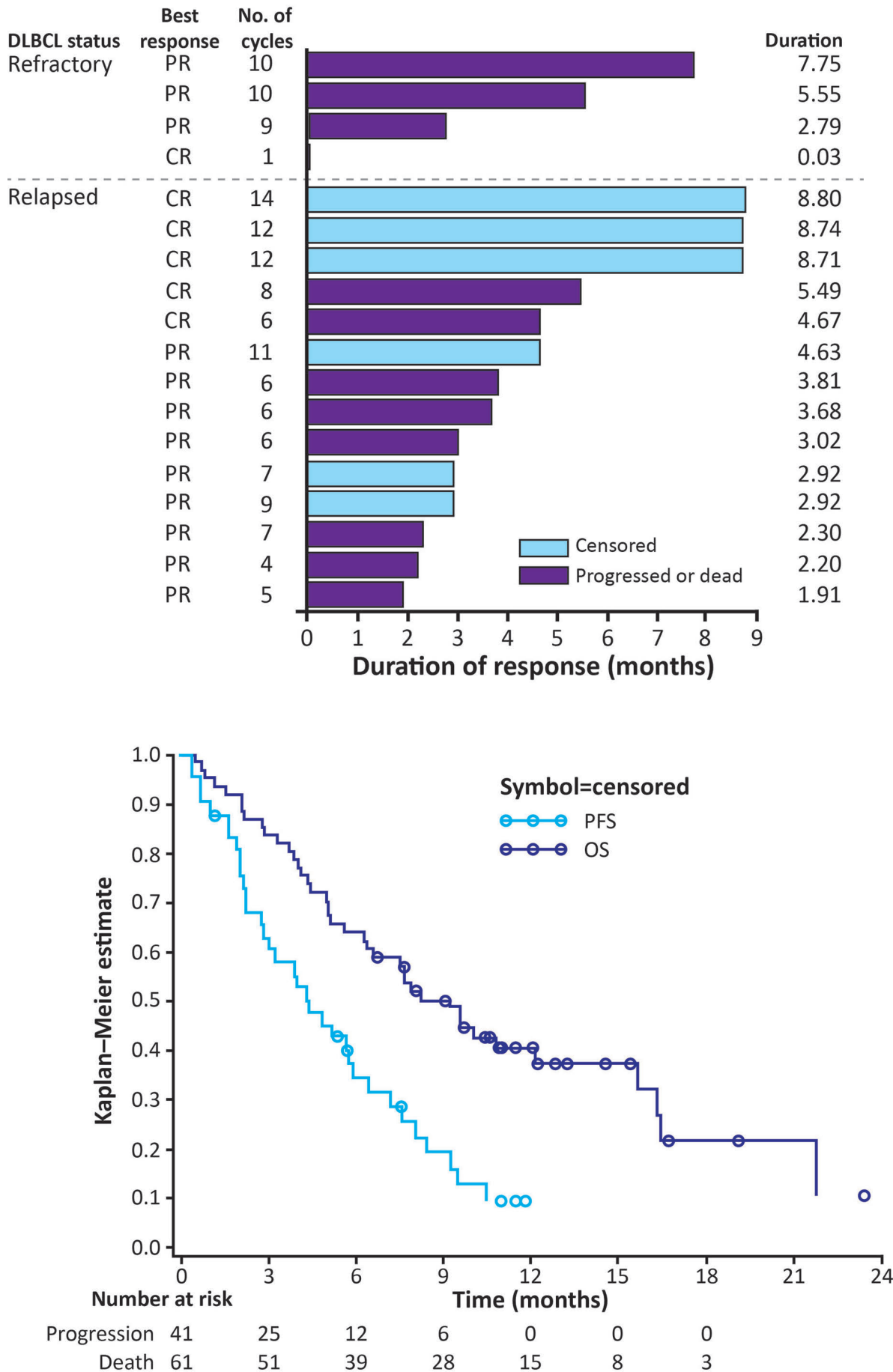

Figure 2. Duration of response for individual patients in the per protocol population. Patients with a duration of response of 0.03 months were censored to the first documentation of the response, in the absence of another evaluable assessment before the cut-off date. CR: complete response; DLBCL: diffuse large B-cell lymphoma; PR: partial response.
Figure 3. Kaplan-Meier curve of progression-free survival (PFS) (per protocol population) and overall survival (OS) (safety population). 
7 patients (11\%). Five patients (8\%) reported peripheral neuropathy $(\mathrm{PN})$ occurring during cycle $1(\mathrm{n}=3)$ or cycle 2 $(\mathrm{n}=2)$, including one case of grade $3 \mathrm{PN}$ (unrelated to study treatment) in a patient with a history of the condition. Dose modifications were not required in any of the patients with $\mathrm{PN}$, although none of these events had resolved at the time of analysis. A further 2 patients presented with events compatible with optic neuropathy (grade 1); this diagnosis was not confirmed, but could not be confidently excluded. Neither of these patients required a dose modification and both events resolved within a median of 9 days (range 4-14). Overall, infusionrelated reactions occurred in 10 patients $(16 \%)$, and were most commonly gastrointestinal in nature (nausea 10\%, vomiting 3\%). Drug hypersensitivity was observed in one patient.

Dose modifications (dose omission, interruption, or cycle delay) due to AEs were required in 17 patients $(28 \%)$, including 9 patients $(15 \%)$ who experienced a grade $3-4$ AE. Nine patients $(15 \%)$ had at least one cycle delayed by $>3$ days, and 9 patients $(15 \%)$ had one dose omitted. One patient $(2 \%)$ required a dose interruption due to grade 1 hypotension, which was considered to be unrelated to treatment.

Of 8 patients $(13 \%)$ who experienced AEs leading to death, 7 were due to PD. The other patient who died developed febrile neutropenia 34 days after the last dose of coltuximab ravtansine while receiving further anticancer therapy (gemcitabine-cisplatin); the investigator could not exclude the possibility that the event was due to a delayed effect of coltuximab ravtansine treatment.

\section{Discussion}

The results of this phase II trial indicate that treatment with coltuximab ravtansine as monotherapy is associated with moderate clinical responses in a proportion of DLBCL patients previously treated with rituximab-based chemotherapy, and has a favorable toxicity profile.

The responses described here are numerically higher than those reported in a phase II study of coltuximab ravtansine in combination with rituximab [ORR 44\% (90\%CI: $30.6-57.9 \%)$ vs. $31 \%$ (90\%CI: $22.0-41.6 \%$ ), respectively]. ${ }^{29}$ However, patients enrolled in the combination study were limited to 3 cycles of treatment, whereas in the current study patients continued on therapy until disease progression or discontinuation due to an $\mathrm{AE}$ or investigator's decision. Additionally, the patients in the combination therapy study could be described as a more refractory population ( $60 \%$ of patients had primary refractory disease), whereas the primary analysis population for the current study excluded patients with primary refractory disease. It should be noted that some patients with primary refractory disease were wrongly included in this study due to a misclassification of their prior treatment history. The response rates described here are in line with other antibody-drug conjugates, when tested as monotherapy $(44-56 \%)^{30,31}$ or in combination with rituximab (29-54\%). ${ }^{32,33}$ Interestingly, the anti-CD30 antibodydrug conjugate brentuximab vedotin achieved an ORR of $44 \%$ among patients with R/R DLBCL, most of whom were refractory to their first $(76 \%)$ and last $(82 \%)$ line of therapy. ${ }^{30}$ The response rates were also similar to antiCD19 monoclonal antibodies, such as MEDI-551,
Table 3. Adverse events (AEs) occurring in $\geq 10 \%$ of patients (safety population; $\mathrm{n}=61)$.

\begin{tabular}{lccc} 
AE, n (\%) & All grades & Grade 3-4 & Grade 5 \\
Any AE & $61(100 \%)$ & $23(38 \%)$ & $8(13 \%)$ \\
Serious AEs & $24(39 \%)$ & $14(23 \%)$ & $8(13 \%)$ \\
\hline AE leading to dose modification* & $17(28 \%)$ & $9(15 \%)$ & - \\
AE leading to discontinuation & $4(7 \%)$ & 0 & - \\
\hline Non-hematologic AEs & & & \\
Asthenia/fatigue & $18(30 \%)$ & $1(2 \%)$ & 0 \\
Nausea & $14(23 \%)$ & $1(2 \%)$ & 0 \\
Diarrhea & $12(20 \%)$ & 0 & 0 \\
Cough & $11(18 \%)$ & 0 & 0 \\
Vomiting & $8(13 \%)$ & 0 & 0 \\
Decreased appetite & $8(13 \%)$ & 0 & 0 \\
Disease progression & $8(13 \%)$ & $3(5 \%)$ & $5(8 \%)$ \\
Back pain & $7(11 \%)$ & $1(2 \%)$ & 0 \\
Abdominal pain & $7(11 \%)$ & $2(3 \%)$ & 0 \\
Dyspnea & $6(10 \%)$ & $1(2 \%)$ & 0 \\
Constipation & $6(10 \%)$ & 0 & 0 \\
Peripheral edema & $6(10 \%)$ & 0 & 0
\end{tabular}

\begin{tabular}{lccc}
$\begin{array}{l}\text { Laboratory abnormalities } \\
\text { Hematologic AEs }\end{array}$ & & \\
Anemia & $53(87 \%)$ & $4(7 \%)$ & - \\
Lymphopenia & $41(67 \%)$ & $13(21 \%)$ & - \\
Leukopenia & $39(64 \%)$ & $9(15 \%)$ & - \\
Thrombocytopenia & $35(57 \%)$ & $6(10 \%)$ & - \\
Neutropenia & $32(52 \%)$ & $15(25 \%)$ & - \\
\hline
\end{tabular}

Hepatic and renal abnormalities

$\begin{array}{lccc}\text { AST } & 37(61 \%) & 2(3 \%) & - \\ \text { Alkaline phosphatase } & 26(45 \%) & 2(3 \%) & - \\ \text { ALT } & 27(44 \%) & 2(3 \%) & - \\ \text { Creatinine } & 19(31 \%) & 2(3 \%) & - \\ \text { Bilirubin } & 9(15 \%) & 1(2 \%) & -\end{array}$

ALT: alanine aminotransferase; AST: aspartate aminotransferase. *Including dose omission, interruption, and cycle delays. 'Laboratory evaluations. ${ }^{\circ} \mathrm{N}=58$.

MOR208, and blinatumomab, currently in phase II development for DLBCL. ${ }^{34-36}$ In comparison, in a recent multicenter, randomized study of the aza-anthracenedione pixantrone in patients with aggressive B-cell lymphoma (DLBCL, transformed indolent lymphoma, or follicular lymphoma), ${ }^{37}$ the ORR was $26 \%$ (CR, $15 \%$ ), with a median PFS of 5.7 months (95\%CI: 2.4-6.5).

The response rates among patients refractory to their first or last line of therapy were numerically lower than those observed among the relapsed patients included in the study (21.4\% and $26.7 \%$ vs. $53.8 \%$, respectively). However, given the limited numbers of patients in each group it is difficult to draw firm conclusions.

Biomarker analysis revealed no apparent correlation between cell of origin classification or MYC/BCL2 expression and clinical response. In addition, none of the CD19 expression measures analyzed showed good predictive accuracy for distinguishing responders and non-responders, and no significant optimal cut-off point for CD19 expression could be identified. This lack of correlation between CD19 expression and efficacy is counterintuitive, but may represent an effect of coltuximab ravtansine on the tumor microenvironment that is important for lymphoma cell growth and survival..$^{38}$ Additional ad hoc analyses would be required to investigate this further. Interestingly, pre-clinical studies have also demonstrated 
that low levels of CD22 or CD79B expression on target cells does not reduce the antitumor activities of pinatuzumab vedotin or polatuzumab vedotin, respectively. ${ }^{39}$ Similar findings have also been reported in a brentuximab vedotin phase II study in DLBCL, in which responses were not dependent on CD30 expression. ${ }^{30}$

Overall, coltuximab ravtansine exhibited a favorable safety profile, with the majority of the most common AEs reported at grade 1-2. The most frequent grade 3-4 AEs were hematologic or gastrointestinal in nature. No studyonset occurrences of grade 3-4 PN or ocular toxicity were observed, and grade 1-2 toxicities were reversible and manageable. In addition, the majority of these events occurred during cycles 1-2 suggesting that they may result from the more intensive dosing of coltuximab ravtansine during the first cycle of the study, rather than drug accu- mulation. Indeed Ribrag et al. ${ }^{19}$ demonstrated a reduced incidence of ocular toxicities and PN with the optimized schedule used here versus a weekly dosing schedule. Dose modifications were required in $28 \%$ of patients due to AEs, approximately half of which were grade 3-4. No dose reductions were required during the study. SAEs considered related to study treatment were uncommon.

In conclusion, the results of this phase II study indicate that the optimized dosing regimen of coltuximab ravtansine may have some efficacy in patients with relapsed or refractory DLBCL, previously treated with rituximab.

\section{Acknowledgments}

The authors would like to thank Amy-Leigh Johnson, PhD, of Adelphi Communications Ltd. (Bollington, UK) for editorial support. This study and the editorial support were funded by Sanofi.

\section{References}

1. Sant M, Allemani C, Tereanu C, et al. Incidence of hematologic malignancies in Europe by morphologic subtype: results of the HAEMACARE project. Blood. 2010;116(19):3724-3734.

2. Montoto S, Fitzgibbon J. Transformation of indolent B-cell lymphomas. J Clin Oncol. 2011;29(14):1827-1834.

3. Dunleavy K, Wilson WH. Appropriate management of molecular subtypes of diffuse large B-cell lymphoma. Oncology (Williston Park). 2014;28(4):326-334.

4. Green TM, Young KH, Visco C, et al. Immunohistochemical double-hit score is a strong predictor of outcome in patients with diffuse large B-cell lymphoma treated with rituximab plus cyclophosphamide, doxorubicin, vincristine, and prednisone. J Clin Oncol. 2012;30(28):3460-3467.

5. Johnson NA, Slack GW, Savage KJ, et al. Concurrent expression of MYC and BCL2 in diffuse large B-cell lymphoma treated with rituximab plus cyclophosphamide, doxorubicin, vincristine, and prednisone. J Clin Oncol. 2012;30(28):3452-3459.

6. Tilly H, Gomes da SM, Vitolo U, et al. Diffuse large B-cell lymphoma (DLBCL): ESMO Clinical Practice Guidelines for diagnosis, treatment and follow-up. Ann Oncol. 2015;26 Suppl 5:v116-v125.

7. Staiger AM, Ziepert M, Horn $\mathrm{H}$, et al. Clinical impact of the cell-of-origin classification and the MYC/BCL2 dual expresser status in diffuse large B-cell lymphoma treated within prospective clinical trials of the German High-Grade Non-Hodgkin's Lymphoma Study Group. J Clin Oncol. 2017;35(22):2515-2526.

8. Petrella T, Copie-Bergman C, Briere J, et al. BCL2 expression but not MYC and BCL2 coexpression predicts survival in elderly patients with diffuse large B-cell lymphoma independently of cell of origin in the phase 3 LNH03-6B trial. Ann Oncol. 2017;28(5): 1042-1049.

9. Sehn LH, Berry B, Chhanabhai M, et al. The revised International Prognostic Index (R-IPI) is a better predictor of outcome than the standard IPI for patients with diffuse large B-cell lymphoma treated with RCHOP. Blood. 2007;109(5):1857-1861.

10. Zhou Z, Sehn LH, Rademaker AW, et al. An enhanced International Prognostic Index (NCCN-IPI) for patients with diffuse large $\mathrm{B}$-cell lymphoma treated in the rituximab era. Blood. 2014;123(6):837-842.

11. Dunleavy K, Fanale M, Lacasce A, et al. Preliminary report of a multicenter prospective phase II study of DA-EPOCH-R in MYC-rearranged aggressive B-cell lymphoma. 56th American Society of Hematology (ASH) Annual Meeting and Exposition, San Francisco, CA, USA, December 6-9, 2014.

12. Wilson WH, Jung SH, Pitcher BN, et al. Phase III randomized Study of R-CHOP versus DA-EPOCH-R and molecular analysis of untreated diffuse large B-cell lymphoma: CALGB/Alliance 50303. Blood. 2016;128 (22):469.

13. Vitolo U, Trneny $M$, Belada $D$, et al. Obinutuzumab or rituximab plus cyclophosphamide, doxorubicin, vincristine, and prednisone in previously untreated diffuse large B-cell lymphoma. J Clin Oncol. 2017:JCO2017733402.

14. Arakaki H, Nakazato T, Osada Y, Ito C, Aisa Y, Mori T. Comparison of R-CVP with R-CHOP for very elderly patients aged 80 or over with diffuse large B cell lymphoma. Ann Hematol. 2017;96(7):1225-1226.

15. Nolasco-Medina D, Reynoso-Noveron N, Mohar-Betancourt A, Aviles-Salas A, Garcia-Perez O, Candelaria M. Comparison of three chemotherapy regimens in elderly patients with diffuse large B cell lymphoma: experience at a single national reference center in Mexico. Biomed Res Int. 2016;2016: 9817606.

16. Gisselbrecht C, Glass B, Mounier N, et al. Salvage regimens with autologous transplantation for relapsed large B-cell lymphoma in the rituximab era. J Clin Oncol. 2010;28(27):4184-4190.

17. Van Den Neste E, Schmitz N, Mounier N, et al. Outcomes of diffuse large B-cell lymphoma patients relapsing after autologous stem cell transplantation: an analysis of patients included in the CORAL study. Bone Marrow Transplant. 2017;52(2):216221.

18. Raufi A, Ebrahim AS, Al-Katib A. Targeting CD19 in B-cell lymphoma: emerging role of SAR3419. Cancer Manag Res. 2013;5:225233 .

19. Ribrag V, Dupuis J, Tilly H, et al. A doseescalation study of SAR3419, an anti-CD19 antibody maytansinoid conjugate, administered by intravenous infusion once weekly in patients with relapsed/refractory B-cell non-Hodgkin lymphoma. Clin Cancer Res. 2014;20(1):213-220.

20. Younes A, Kim S, Romaguera J, et al. Phase I multidose-escalation study of the antiCD19 maytansinoid immunoconjugate SAR3419 administered by intravenous infusion every 3 weeks to patients with relapsed/refractory B-cell lymphoma. J Clin Oncol. 2012;30(22):2776-2782.

21. Cheson BD, Pfistner B, Juweid ME, et al. Revised response criteria for malignant lymphoma. J Clin Oncol. 2007;25(5):579. 586.

22. Advani A, Coiffier B, Czuczman MS, et al Safety, pharmacokinetics, and preliminary clinical activity of inotuzumab ozogamicin, a novel immunoconjugate for the treatment of B-cell non-Hodgkin's lymphoma: results of a phase I study. J Clin Oncol. 2010;28(12):2085-2093.

23. Wiernik PH, Lossos IS, Tuscano JM, et al. Lenalidomide monotherapy in relapsed or refractory aggressive non-Hodgkin's lymphoma. J Clin Oncol. 2008;26(30):49524957.

24. Witzig TE, Reeder CB, LaPlant BR, et al. A phase II trial of the oral mTOR inhibitor everolimus in relapsed aggressive lymphoma. Leukemia. 2011;25(2):341-347.

25. Witzig TE, Vose JM, Zinzani PL, et al. An international phase II trial of single-agent lenalidomide for relapsed or refractory aggressive B-cell non-Hodgkin's lymphoma. Ann Oncol. 2011;22(7):1622-1627.

26. Hernandez-Ilizaliturri FJ, Deeb G, Zinzani $\mathrm{PL}$, et al. Higher response to lenalidomide in relapsed/refractory diffuse large B-cell lymphoma in nongerminal center B-celllike than in germinal center B-cell-like phenotype. Cancer. 2011;117(22):5058-5066.

27. Friedberg JW, Sharman J, Sweetenham J, et al. Inhibition of Syk with fostamatinib disodium has significant clinical activity in non-Hodgkin lymphoma and chronic lymphocytic leukemia. Blood. 2010;115(13): 2578-2585.

28. Dunleavy K, Pittaluga S, Czuczman MS, et al. Differential efficacy of bortezomib plus chemotherapy within molecular subtypes of diffuse large B-cell lymphoma. Blood. 2009;113(24):6069-6076.

29. Coiffier B, Thieblemont C, de GS, et al. A 
M. Trněný et al.

phase II, single-arm, multicentre study of coltuximab ravtansine (SAR3419) and rituximab in patients with relapsed or refracttory diffuse large B-cell lymph
Haematol. 2016;173(5):722-730.

30. Jacobsen ED, Shaman JP, Oke Y, et al. Brentuximab vedotin demonstrates objecrive responses in a phase 2 study of relapsed/refractory DLBCL with variable 1402

31. Palanca-Wessels MC, Czuczman M, Gales $G$, et al. Safety and activity of the antiCD79B antibody-drug conjugate polatuzumab vedotin in relapsed or refractory lymphocytic leukaemia: a phase 1 study. Lancet Oncol. 2015;16(6):704-715.

32. Morschhauser F, Fin I, Advani RH, et al. Preliminary results of a phase II randomized study (ROMULUS) of polatuzumab
vedotin (PoW) or pinatuzumab vedotin (RiV) plus rituximab (RTX) in patients (Pts) with relapsed/refractory (R/R) nonHodgkin lymphoma (NHL). American
Society of Clinical Oncology (ASCO), Chicago, IL, USA, May 30-June 3, 2014 Abstract 8519

33. Wagner-Johnston ND, Goy A, Rodriguez $\mathrm{MA}$, et al. A phase 2 study of inotuzumab ozogamicin and rituximab, followed by autologous stem cell transplant in patients with relapsed/refractory diffuse large B-cell lymphoma.

34. Viardot A, Goebeler M, Hess G, et al. Treatment of relapsed/refractory diffuse large B-cell lymphoma with the bispecific Tcell engager ( $T$ TE) antibody construct blinitumomab: primary analysis results from an Society of Hematology (ASH) Annual Meeting and Exposition, San Francisco, CA, USA, December 6-9, 2014. Abstract 4460.

35. Goswami T, Forero A, Hamadan M, et al. Phase I/II study of MEDI-551, a humanized
monoclonal antibody targeting CD 19, in subjects with relapsed or refractory advanced B-cell malignancies. American Society of Clinical Oncology (ASCO),
Chicago, IL, USA, June 1-5, 2012. Abstract 8065

36. Jurczak W, Zinzani PL, Goy A, et al. Phase Ila study of single-agents MOR208 in patients with relapsed or refractory B-cell non-Hodgkin's lymphoma (NHL). ASCO Annual Meeting, Chicago, IL, USA, May 29-June 2, 2015. Abstract 8500.

37. Pettengell R, Coiffier B, Narayanan G, et al. Pixantrone dimaleate versus other chemotherapeutic agents as a single-agent salvage treatment in patients with relapsed
or refractory aggressive non-Hodgkin lymphoma: a phase 3 , multicentre, randomised trial. Lancet Oncol. 2012;13(7) randomised

38. Chain KH, Dalton WS, Tao J. The tumor microenvironment shapes hallmarks of mature B-cell malignancies. Oncogene. 2015;34(36):4673-4682.

. Pfeifer M, Zheng B, Erdmann T, et al. AntiCD22 and anti-CD79B antibody drug conjugate are active in different molecular iffuse large B-cell lymphoma subtypes. Leukemia. 2015;29(7):1578-1586.

1358

haematological | 2018; 103(8) 